\title{
Studies of silicon photoelectrochemical cells under high injection conditions
}

Amit Kumar and Nathan S. Lewis ${ }^{2)}$

Division of Chemistry and Chemical Engineering, California Institute of Technology, Pasadena, California 91125

(Received 2 July 1990; accepted for publication 21 September 1990)

The behavior of $\mathrm{Si} / \mathrm{CH}_{3} \mathrm{OH}$-dimethylferrocene ${ }^{+/ 1}$ junctions has been investigated under high injection conditions. Open circuit voltages of $(626 \pm 5) \mathrm{mV}$ were obtained at short circuit photocurrent densities of $20 \mathrm{~mA} / \mathrm{cm}^{2}$ for samples with an $n^{+}$-diffused back region, point contacts on the back surface, and with a base of thickness $390 \mu \mathrm{m}$ and a 1 ms hole lifetime. The diode quality factor and recombination current density were $1.8 \pm 0.1$ and (2.6 \pm 1.5$) \times 10^{-8} \mathrm{~A} / \mathrm{cm}^{2}$, respectively. These data are consistent with recombination dominated by the base and back contact regions, and not at the $\mathrm{Si} / \mathrm{CH}_{3} \mathrm{OH}$ interface.

We have previously shown that $n-\mathrm{Si} / \mathrm{CH}_{3} \mathrm{OH}$ interfaces are of remarkable electronic quality, and exhibit open circuit voltages that are superior to those obtained from $\mathrm{Si} /$ metal junctions and from conventional $\mathrm{Si} p-n$ homojunctions. ${ }^{1-3}$ Over a range of Si dopant densities and diffusion lengths, the open circuit voltage $\left(V_{n c}\right)$ for $n-S i /$ $\mathrm{CH}_{3} \mathrm{OH}$-dimethylferrocene $\left(\mathrm{Me}_{2} \mathrm{Fc}\right)^{+/ 0}$ junctions follows the Shockley diode equation, 2,3 as expected for a junction in which interfacial recombination losses are negligible compared to the minority-carrier bulk diffusion/ recombination process. ${ }^{4}$ Since these previous systems were operated under low-level injection conditions, the trade-off between high donor densities $\left(N_{d}\right)$ and maximum minority-carrier difusion lengths $\left(L_{p}\right)$ resulted in maximum $n-\mathrm{Si} / \mathrm{CH}_{3} \mathrm{OH} V_{\text {oc }}$ values of $635 \mathrm{mV}$ (light-limited photocurrent density, $J_{\mathrm{ph}}=20 \mathrm{~mA} / \mathrm{cm}^{2}, 298 \mathrm{~K}$ ) for $N_{d}=3.2 \times 10^{16} \mathrm{~cm}^{-3} n$-Si with $L_{p}=195 \mu \mathrm{m}$, while higher $V_{\text {oc }}$ values of $670 \mathrm{mV}\left(J_{\mathrm{ph}}=20 \mathrm{~mA} / \mathrm{cm}^{2}, 298 \mathrm{~K}\right)$ for $N_{d}=1.8 \times 10^{17} \mathrm{~cm}^{-3} n$-Si were only achieved with a concurrent degradation of base lifetime $\left(L_{p}=20 \mu \mathrm{m}\right) .^{3}$ An alternative design exploited recently in solid-state Si photovoltaics to preserve high base lifetimes is to operate the base region under field-free, high injection conditions. ${ }^{5}$ This approach has allowed fabrication of high eficiency $\left(>22 \%\right.$ ) photovoltaic cells displaying air mass $1.0 V_{o c}$ values as high as $705 \mathrm{mV}{ }^{6}$ We now report studies of $n-\mathrm{Si}$ / liquid junctions operated under high injection conditions. These cells take advantage of the electronic quality of the $\mathrm{Si} / \mathrm{CH}_{3} \mathrm{OH}$ interface, and have resulted in $630 \mathrm{mV} V_{\text {oc }}$ values (on unoptimized base/back contact combinations) with no processing steps performed on the liquid side of the Si base region. In addition to advancing our basic knowledge of the electronic properties of semiconductor/liquid junctions, these Si/liquid systems might be useful for simple, nondestructive, spatially resolved diagnostics of Si base quality.

Figure 1 depicts the liquid junction cell. The semiconductor photoelectrode (typically squares of edge dimension $6-8 \mathrm{~mm}$ ) consisted of an intrinsic Si layer ( $390 \mu \mathrm{m}$ thick, $N_{d}=1.3 \times 10^{13} \mathrm{~cm}^{-3}$; low-level hole lifetime $=1$ $\mathrm{ms}$ ), with an $n^{+}$-type diffused layer (sheet resistivity $=40$

\footnotetext{
address correspondence to this author.
}

$\Omega / \square)$ on the back side of the wafer. Contact to the $n^{+}$ layer was achieved by an array of metal points $(5 \mu \mathrm{m} \times 5$ $\mu \mathrm{m}$ squares) covering $2 \%$ of the active device area. The remaining back surface area of the wafer was covered by a high quality thermally grown $\mathrm{SiO}_{2}$ layer. This structure is similar to the processing used in high efficiency $p-i-n$ solidstate concentrator cells, 5,6 and reduces parasitic recombination losses in the diffused region and at the back surface. For use in the liquid junction arrangement, no processing or difusion steps were performed on the front surface; the Si samples were merely etched in $49 \% \mathrm{HF}(\mathrm{aq})$ and were rinsed with $\mathrm{H}_{2} \mathrm{O}$ and $\mathrm{CH}_{3} \mathrm{OH}$ before use in a conventional photoelectrochemical cell arrangement. ${ }^{3,7}$ For comparison purposes, a complete $p-i-n$ cell was evaluated in parallel with the Si/liquid junctions. This $p-i-n$ cell was not fabricated in the identical batch process as the structures examined in the liquid junction, but it nominally had the same back contact and base characteristics, with a front emitter consisting of an $80 \Omega /\left[p^{+}\right.$region with point contacts, oxide passivation, and a textured front surface for light trapping purposes. The p-i-n test cell behavior was typical of such devices, although optimized cells with higher hole lifetimes and thinner bases have been reported to display slightly larger $V_{o c}$ values. ${ }^{6}$

Figure 2 displays the current-voltage (I-V) behavior at

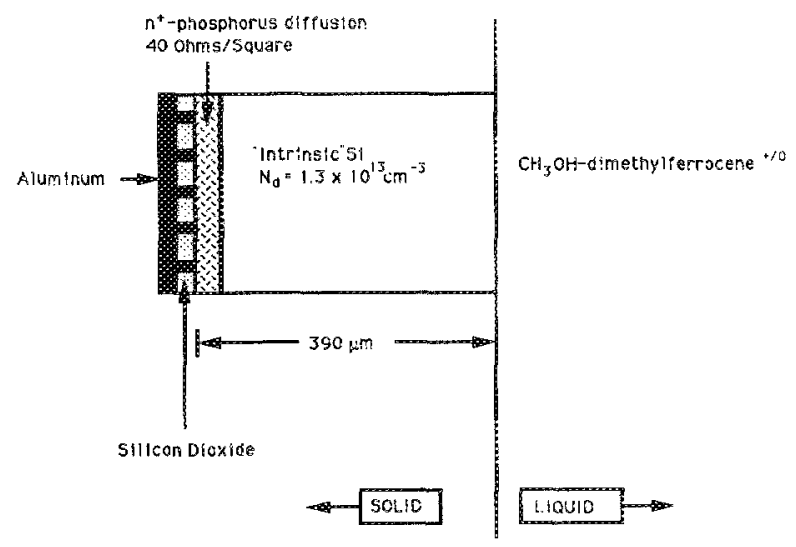

FIG. 1. Schematic diagram of photoelectrode used in this study. Contact to the electrode was made through the Al back, and the electrode edges and back surface were encapsulated in epoxy to expose $0.4-0.6 \mathrm{~cm}^{2}$ of active area to the electrolyte. 


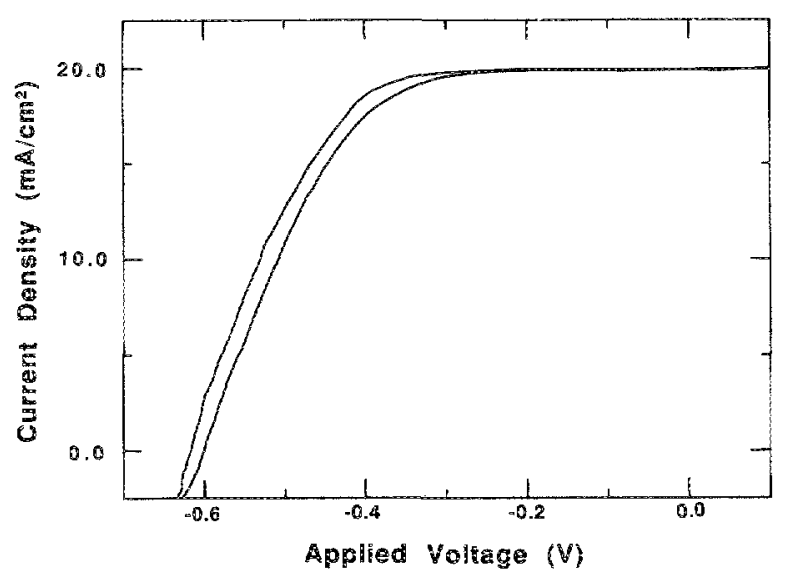

FIG. 2. Potentiostatic three-electrode current-voltage ( $I-D)$ property of high injection $\mathrm{Si} / \mathrm{CH}_{3} \mathrm{OH}-\mathrm{Me}_{2} \mathrm{Fe}^{+/} / 0$ photoelectrochemical cell. The reference electrode was a $P t$ wire in a Luggin capillary placed $0.2 \mathrm{~mm}$ from the photoelectrode surface. The counter electrode was a large area $(>3$ $\mathrm{cm}^{2}$ ) Pt foil. The poor fill factor is due to the concentration overpotential and to the large residual uncompensated resistance of the solution in this unoptimized semiconductor/liquid cell configuration.

$298 \mathrm{~K}$ of the Si photoelectrode in contact with the $\mathrm{CH}_{3} \mathrm{OH}-1.0 \mathrm{M} \mathrm{LiClO}-0.20 \mathrm{M}$ dimethylferrocene ( $\left.\mathrm{Me}_{2} \mathrm{Fc}\right)-0.010 \mathrm{M} \mathrm{Me}_{2} \mathrm{Fc}^{+}$electrolyte. The $\mathrm{Me}_{2} \mathrm{Fc}^{+/ 0} \mathrm{re}-$ dox system established the Fermi level of the liquid phase, and insured a high degree of equilbrium band bending in the Si base while maintaining electrode stability to photocorrosion. ${ }^{7,8}$ The Si surface in the liquid junction was not optimized for light trapping or for minimization of optical reflection losses; thus, to facilitate comparison of electrical properties with the solid-state $p-i-n$ test cell, the light intensity was adjusted to provide short circuit photocurrent densities $\left(J_{\mathrm{ph}}\right)$ of $20.0 \mathrm{~mA} / \mathrm{cm}^{2}$. Under these conditions, the $V_{\text {oc }}$ of $626 \pm 5 \mathrm{mV}$ obtained from the liquid junctions compares closely to the $V_{\text {oc }}$ of $625 \mathrm{mV}$ measured for the $p-i-n$ device at $y_{p h}=20 \mathrm{~mA} / \mathrm{cm}^{2}$. This indicates that the ratio of minority-carrier collection to majority-carrier recombination is similar in the two systems, and underscores the high electronic quality of the $\mathrm{HF}$-etched $\mathrm{Si} / \mathrm{CH}_{3} \mathrm{OH}$ junction. The $V_{\text {oc }}$ values reported for the liquid junctions are statistically averaged results from 3 diferent Si samples used in a total of 11 separate $\mathrm{S} / / \mathrm{CH}_{3} \mathrm{OH}$ cells. The $\mathrm{Si} /$ $\mathrm{CH}_{3} \mathrm{OH}$ junction in Fig. 2 is clearly operating in high-level injection, because the low-level injection bulk recombination/diffusion $V_{o c}$ value for $N_{d}=1.3 \times 10^{13}$ $\mathrm{cm}^{-3}$ Si with an effective minority-carrier diffusion length of $400 \mu \mathrm{m}$ is only $473 \mathrm{mV}$ at $J_{\mathrm{ph}}=20 \mathrm{~mA} / \mathrm{cm}^{2}$. Under these conditions, a $V_{\text {oc }}$ higher than this $473 \mathrm{mV}$ value can only be achieved if the injected majority-carrier density exceeds the equilibrium majority-carrier density, implying that the high injection condition has indeed been obtained. The poor fill factor in Fig. 2 results from the uncompensated resistance losses and concentration overpotentials that are inherent to an unoptimized liquid junction cell design. The $V_{o c}$ values for such systems are still useful, because use of a thin layer cell configuration has been shown to minimize these cell-based losses while still pre-

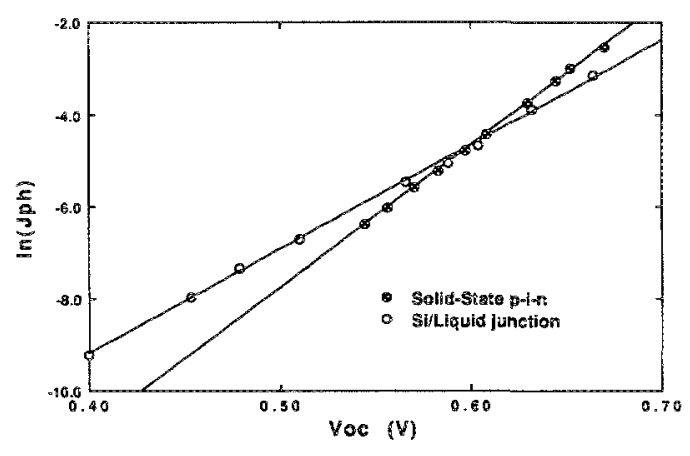

FIG. $3 . \ln \left(J_{p h}\right)$ vs $V_{\text {oc }}$ for the solid-state $p-i-n$ cell (dark circles) and for the photoelectrochemical cell (light circles). In this figure the ordinate is the natural logaritim of $J_{\mathrm{ph}}$ measured in $\mathrm{A} / \mathrm{cm}^{2}$. The $V_{t e}$ for the liquid junction cell becomes greater than that for the $p-i-n$ cell at high currert densities.

serving the $V_{n c}$ determined in the unoptimized cell arrangement used in Fig. 2.

Plots of the dependence of $V_{o c}$ on the light-limited pho. tocurrent density for $J_{\mathrm{ph}}=0.10-50 \mathrm{~mA} / \mathrm{cm}^{2}$ are presented in Fig. 3 for both the $n-\mathrm{Si} / \mathrm{CH}_{3} \mathrm{OH}$ junction and the $p-i-n$ test cell. Analysis of the data using the standard diode relationship ${ }^{4}$

$$
V_{\mathrm{oc}}=(A k T / q) \ln \left(J_{\mathrm{ph}} / J_{0}\right)
$$

(where $A$ is the diode quality factor, $k T / q$ is the thermal voltage, $J_{\mathrm{ph}}$ is the light-limited photocurrent density, and $J_{0}$ is the magnitude of the recombination current density) yielded values of $J_{0}=7.9 \times 10^{-11} \mathrm{~A} / \mathrm{cm}^{2}$ and $A=1.2$ for the $p-i-n$ cell, and $J_{0}=(2.8 \pm 1.6) \times 10^{-8} \mathrm{~A} / \mathrm{cm}^{2}$ and $A=1.8 \pm 0.1$ for the liquid junction. The dominant recombination mechanism for the $p-i-n$ test cell has been assigned previously to recombination in the difused regions of the device, leading to the observed $A$ and $J_{0}$ values for the solid-state system. ${ }^{5}$ In contrast, the liquid junction has no front diffused region, but consists of a high quality Si/ liquid interface. The higher $A$ value in the Si/hiquid cell reffects this lack of front emitter recombination loss. For the relatively thick Si base ( $390 \mu \mathrm{m})$ with a $1 \mathrm{~ms}$ minoritycarrier lifetime, recombination in the base region is expected to determine the device properties provided that the front emitter recombination can be suppressed. This is in accord with the observed $A$ and $J_{0}$ values of the $\mathrm{Si} / \mathrm{CH}_{3} \mathrm{OH}$ junction. At high light intensities, use of the liquid contact to eliminate front emitter recombination results in higher $V_{o c}$ values for the $n-\mathrm{Si} / \mathrm{CH}_{3} \mathrm{OH}$ junction than for the test $p-i-n$ cell. Variation in processing to achieve further reductions in base recombination, such as using longer lifetime Si samples with thinner base regions, might allow air mass $1.0 V_{\alpha}$ values of $\mathrm{Si} / \mathrm{CH}_{3} \mathrm{OH}$ junctions to be competitive with the $705 \mathrm{mV}$ values obtained from optimized $p^{-i-n}$ structures.

Considering the high concentration of both electron donors $\left(\mathrm{Me}_{2} \mathrm{Fc}\right)$ and acceptors $\left(\mathrm{Me}_{2} \mathrm{Fc}^{+}\right)$in the liquid phase, it is remarkable that the $n-\mathrm{Si} / \mathrm{CH}_{3} \mathrm{OH}$ cell displays such large $V_{o c}$ values under high injection conditions. The spectral response behavior, displayed in Fig. 4, underscores 


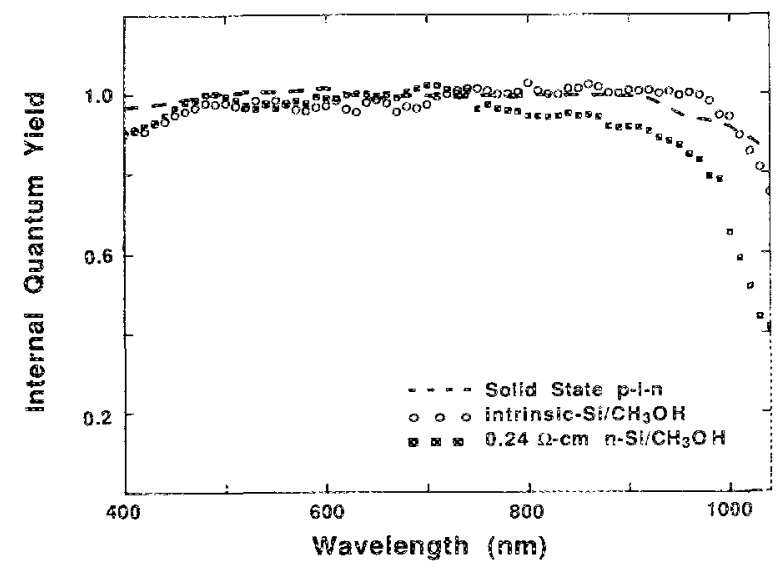

FIG. 4. Internal short circuit quantum yield vs wavelength for the $p-i-n$ cell (dashed line, last part of Ref. 5), the intrinsic Si liquid junction (light circles), and for a $N_{d}=3.2 \times 10^{16} \mathrm{~cm}^{-3}$, foat zone grown, $n-\mathrm{Si}$ sample $\left(L_{p}=195 \mu \mathrm{m}\right)$. The concentrations of redox ions for the liquid junctions were $0.001 \mathrm{M} \mathrm{Me} \mathrm{Fc}_{2}$ and $0.000 \mathrm{M} \mathrm{Me}_{2} \mathrm{Fc}^{+}$.

the excellent hole collection properties of this junction. Figure 4 compares the internal quantum yield of the $n-\mathrm{Si}$ / $\mathrm{CH}_{3} \mathrm{OH}$ interface using $N_{d}=1.3 \times 10^{13} \mathrm{~cm}^{-3}$ and $N_{d}=3.2 \times 10^{16} \mathrm{~cm}^{-3}$ Si samples to that for a typical $N_{d}=1.3 \times 10^{13} \mathrm{~cm}^{-3}$ base $p-i-n$ cell. In the longwavelength region, the internal quantum eficiency of the $N_{d}=1.3 \times 10^{13} \mathrm{~cm}^{-3} n-\mathrm{Si} / \mathrm{CH}_{3} \mathrm{OH}$ junction is substantially higher than that of the $N_{d}=3.2 \times 10^{16} \mathrm{~cm}^{3}$ sample $^{3}$ and is comparable to the response of the $p-i-n \mathrm{Si}$ test ceil. This behavior correlates with the larger effective minority. carrier diffusion length in the low-doped Si samples. For the mirror-finished Si surfaces used in contact with liquids, the maximum absolute external quantum yield of the $n$-Si/ $\mathrm{CH}_{3} \mathrm{OH}$ interface was $0.75-0.80$; however, it has been shown that surface texturizing etches can yield improvements in maximum external quantum yield to greater than 0.95 for $N_{d}=3.2 \times 10^{16} \mathrm{~cm}^{-3} n-\mathrm{Si} / \mathrm{CH}_{3} \mathrm{OH}$ junctions. ${ }^{1,7,10}$ Thus, despite the potential for interfacial recombination at the Si/liquid interface, the achievable quantum yields are comparable to maximum external quantum yieids achievable in optinized $p-i-n$ devices. ${ }^{5.6}$

We have also investigated the dependence of $V_{o c}$ on the concentration of donors and acceptors in the liquid phase. The concentration of $\mathrm{Me}_{2} \mathrm{Fc}$ was varied from 0.005 to 0.20 $\mathrm{M}$, the concentration of $\mathrm{Me}_{2} \mathrm{Fc}_{\mathrm{c}}$ was varied from 0.0001 to $0.10 \mathrm{M}$, and the $\left[\mathrm{Me}_{2} \mathrm{Fc}^{+}\right] /\left[\mathrm{Me}_{2} \mathrm{Fc}\right]$ ratio was varied from 20 to $5.0 \times 10^{-4}$. For all combinations studied, and over a range of $J_{\mathrm{ph}}$ from 2.0 to $20 \mathrm{~mA} / \mathrm{cm}^{2}, V_{o c}$ did not change $( \pm 10 \mathrm{mV})$ when the redox concentrations were varied. This is somewhat surprising, because under high injection conditions, carrier rransport in the intrinsic layer should be purely diffusional. With no electric field to repel majority carriers, conventional electron transfer theories $^{11,12}$ predict that the nighly exoergic electron capture by $\mathrm{Me}_{2} \mathrm{FC}^{+}$should be more kinetically facile than the less exoergic hole capture by $\mathrm{Me}_{2} \mathrm{Fc}$. The independence of $V_{\mathrm{oc}}$ with changes in redox concentrations, and the excellent majority-carrier rejection indicated by the spectral response data, both indicate that the rate-limiting recombination step for majority carriers does not involve bimolecular interfacial recombination with the dissolved redox ions. The present data cannot address whether the underlying cause of the high (minority/majority) carrier collection ratio is due to a failure of the conventional MarcusGerischer electron transfer theory ${ }^{11,12}$ in this system or is due to strong surface inversion induced by the $\mathrm{CH}_{3} \mathrm{OH}$ $\mathrm{Me}_{2} \mathrm{Fc}^{+/ 0}$ contact. The latter situation would result in in situ formation of a $p^{+}$-doped layer at the $\mathrm{Si} / \mathrm{CH}_{3} \mathrm{OH}$ interface, making the $p-i-n$ cell and the $\$$ i/hiquid cell very similar in device properties. Experiments designed to distinguish between these alternatives are currently in progress; however, the present data clearly show that the collection properties of the $n-\mathrm{Si} / \mathrm{CH}_{3} \mathrm{OH}$ interface can approach those of the best known solid-state $\mathrm{Si}$ photovoltaic systems.

Although the $n$-Si $/ \mathrm{CH}_{3} \mathrm{OH}$ interface yielded $V_{\text {oc }}$ values that were higher than those in the $p-i-n$ test cell used in this work, this requires operation under high light concentration, where the efficiency performance of a liquid junction suffers relative to solid-state systems. Even in thin (10 $\mu \mathrm{m})$ electrolyte layers, mass transport limitations on the supply of redox couple to the Si interface lead to declines in power conversion efficiency at current densities higher than 50 $\mathrm{mA} / \mathrm{cm}^{2}, 2,9$ which is the range in which the high injection $p-i-n$ devices exhibit superior efficiency performance. ${ }^{6}$ The liquid junction behavior under high injection conditions is valuable, however, in advancing our understanding of carrier transport and recombination at solid/liquid boundaries. It is encouraging to note that the performance of such single-crystal $\mathrm{Si} / \mathrm{CH}_{3} \mathrm{OH}$ interfaces can approach that of the most technologically advanced photovoltaic systems, and that these semiconductor/liquid systems can afrord relatively stable junction performance from simple, available chemicals and liquids.

We thank the National Science Foundation for support of this work. This is contribution No. 8167 from the Caltech Division of Chemistry and Chemical Engineering. We also thank Ronald A. Sinton and Richard M. Swanson of the Stanford Electronics Laboratory (Stanford, CA) for invaluable discussions and for supplying the samples used in this study. A. K. acknowledges the Department of Education for a Research Fellowship.

${ }^{1}$ M. E. Rosenbluth, C. M. Lieber, and N. S. Lewis, Appl. Phys. Lett. 45, 423 (1984)

${ }^{2}$ N. S. Lewis, Ann. Rev. Mater. Sci. 14, 95 (1984).

${ }^{3}$ M. L. Rosenbluth and N. S. Lewis, J. Am. Chem. Soc. 108, 4689 (1986).

${ }^{4}$ W. Shockley, Beil Syst. Tech. I. 28, 435 (1949); A. L. Fahrenbruch and R. H. Bube, Fundamentuls of Solar Cells (Academic, New York, 1983). ${ }^{5}$ R. M. Swanson, Solar Cells $\$ 7,85(1986)$; R. A. Sinton and R. M. Swanson, IEEE Trans. Electron. Devices ED-34, 2116 (1987).

${ }^{6}$ R. R. King, R. A. Sinton, and R. M. Swanson, Appl. Phys. Lett. 54, 1460 (1989).

${ }^{7}$ C. M. Gronet, N. S. Lewis, G. W. Cogan, and J. F. Gibbons, Proc. Nat. Acad. Sci. LSA 80, 1152 (1983).

${ }^{8}$ K. D. Legg, A. B. Ellis, J. M. Bolts, and M. S. Wrighton, Proc. Natl. Acad. Sci. USA 74, 4116 (1977).

I. F. Gibbons, G. W. Cogan, C. M. Gronet, and N. S. Lewis, Appl. Phys. Lett. 45, 1095 (1984).

${ }^{10}$ J. A. Bruce and M. S. Wrighton, J. Electroanal. Chem. 122, 93 (1981).

${ }^{11} \mathrm{H}$. Gerischer, in Physical Chemistry, An Advanced Treatise, edited by $\mathrm{H}$. Y. Eyring, D. Henderson, and W. Yost, 9A, pp. 463-542, 1970.

${ }^{12}$ S. R. Morrison, Electrochemistry at Semiconductor and Oxidized Metal Eletrodes (Plenum, New York, 1981). 